\title{
O CEMITÉRIO COMO ESPAÇO MULTIFUNCIONAL: UM ESTUDO DE CASO EM TANGARÁ DA SERRA - MT
}

\author{
CEMETERY AS A MULTIFUNCTIONAL SPACE: \\ A CASE STUDY IN TANGARÁ DA SERRA - MT
}

\author{
Ana Paula Silva de Andrade \\ Cleci Grzebieluckas \\ Flávio Amaral Oliveira \\ Rodrigo Henrique Pinheiro
}

\begin{abstract}
RESUMO
Os cemitérios são estruturas essenciais para gestão ambiental e ordenamento das cidades e, com sua inclusão no contexto urbano, o espaço a eles destinado vem sendo repensado em favor da conservação ambiental e do paisagismo. Este estudo teve como objetivo analisar a configuração do cemitério municipal de Tangará da Serra - MT, com o objetivo específico de elencar as vantagens e as desvantagens da tipologia tradicional em comparação com a proposta do cemitério parque, por meio de um estudo de caso de natureza descritiva e abordagem qualiquantitativa, baseado em levantamento bibliográfico, visitas in loco e entrevistas informais. Os resultados demonstraram que, na comparação entre os dois modelos, o cemitério horizontal apresenta desvantagens em relação a utilização do espaço e paisagismo, enquanto o segundo, apesar de não ser imediatamente reconhecido como cemitério, tem a contrapartida de sua estrutura ser baseada na ampla arborização, com benefícios ambientais relacionados ao conforto térmico, conservação e beleza cênica.
\end{abstract}

Palavras-chave: Cemitério; Espaço; Gestão ambiental. Paisagem Urbana.

\section{ABStRACt}

Cemeteries are essential structures for environmental management and city planning and with their inclusion in the urban context, the space for them has been rethought in favor of landscaping and environmental conservation. This study aimed to analyze the configuration of Tangará da Serra - MT municipal cemetery, with the specific objective of listing the advantages and disadvantages of the traditional typology compared to the proposal of park cemetery, through a case study of descriptive nature and qualitative approach, based on bibliographic survey, on-site visits and informal interviews. The results demonstrated, in the comparison between the two models, that the traditional cemetery presents disadvantages in relation to the use of space and interference in the landscape, while the second one, despite not being identified as a cemetery, presents the advantage of its structure widely used in afforestation, with environmental benefits issues related to thermal comfort, conservation and scenic beauty.

Key words: Cemetery; Space; Environmental management. Urban landscape. 


\section{INTRODUÇÃo}

A formação do espaço urbano é influenciada por diversos processos e particularidades históricas que direcionam a expansão dos ambientes de forma heterogênea, em grande parte desconsiderando as questões socioambientais relacionadas ao empobrecimento da paisagem e supressão dos elementos naturais (LOBODA \& DE ANGELIS, 2005; ROSA, 2003).

No entanto, a paisagem é uma realidade viva, em contínua transformação, e o sentimento e a noção que dela se tem se conectam à percepção estética da natureza regidos principalmente pelo reconhecimento visual, que possibilita atribuir um significado específico a um determinado local (CONTI, 2014; BARTALINI, 2019; GAFSKI, 2018). Com isso, os cemitérios, locais fortemente marcados pela influência cultural, têm tido seu espaço repensado em função de seu potencial para contribuir com a infraestrutura verde urbana e como garantia de áreas propícias ao paisagismo e à preservação ambiental (CLAYDEN et al., 2015; LOBODA; DE ANGELIS, 2005).

Como espaços livres que ocupam extensões significativas, os cemitérios podem impactar a paisagem de maneira agregadora, quando pensados dentro de um conceito de planejamento ambiental (SANTOS, 2013). As práticas funerárias evoluíram ao longo tempo ao sabor de crenças e circunstâncias econômicas, mas a constante dos problemas estruturais e do potencial de contaminação ambiental determinaram a concepção de diferentes tipologias de cemitérios, como o cemitério horizontal, vertical e parque ou jardim, cada qual apresentando particularidades (PACHECO, 2000; PIZZOL, 2011; KEMERICH et al., 2014).

No que tange à conservação ambiental, a proposta do cemitério parque se destaca por oferecer a opção de evitar a lápide tradicional e o usufruto de uma nova paisagem de cemitério, cujo foco é a natureza (CEMITÉRIO SEM MISTÉRIO, 2017; CLAYDEN et al., 2016). De acordo com Santos (2013), no cemitério parque, se projetado com um ideal paisagístico criterioso, os aspectos microclimáticos agradáveis proporcionados pela vegetação podem se prestar à conservação de biomas da região a que pertencem e para a manutenção de espécies variadas da fauna, tornando-se reduto de tranquilidade e fruição em meio ao caos urbano.

Em Tangará da Serra - MT, como na maior parte do país, o cemitério municipal tem tipologia tradicional horizontal e, devido ao crescimento populacional, o espaço para novas sepulturas escasseia, já existindo uma proposta para implantação de um cemitério parque no município. Frente ao exposto, a pesquisa objetivou analisar a utilização do espaço no cemitério municipal, com objetivo específico de identificar as potencialidades e as fragilidades entre os modelos tradicional e cemitério parque.

Justifica-se o estudo em razão de que tal detalhamento, no âmbito do planejamento ambiental de serviços públicos, pode auxiliar os gestores a repensar o projeto urbano, com inclusão e aproveitamento da estrutura cemiterial (BEECHER, 1996) considerando o atendimento da demanda, a conservação ambiental e a estruturação de um local aprazível para os visitantes.

\section{Referencial Teórico}

\subsection{O ADVENTO DOS CEMITÉRIOS}

A prática dos sepultamentos remonta à Idade Média, quando esses eram realizados dentro e ao redor das igrejas, sem a preocupação com o destino individual dos corpos, então dispostos em sepulturas coletivas sem identificação pessoal. Por razões de saúde pública, no final do século 18 , houve a proibição de sepultamentos nesses locais, o que determinou o advento dos cemitérios (KEMERICH et al., 2014; CLAYDEN et al., 2016; SANTOS; LIMA, 2017).

Os cemitérios tradicionais constituem necrópoles onde os corpos são depositados em túmulos, mausoléus e capelas, que, de modo geral, apresentam considerável custo de construção e manutenção estética e impacto na beleza cênica urbana, aliado à pouca arborização (SILVA, 2001; ROSA, 2003; CAMPOS, 2007). Frequentemente, a possibilidade de contaminação ambiental oriunda do processo de decomposição dos corpos suscita preocupação, pois 
historicamente a implantação de cemitérios tem sido feita em terrenos com condições hidrogeológicas inadequadas, suscetíveis a agravos ambientais (PACHECO, 2000; CARNEIRO, 2008).

A preocupação com tais questões ambientais e a falta de espaço nas grandes cidades ocasionou a idealização de estruturas como os cemitérios verticais, concebidos como prédios acima do solo, onde os corpos são sepultados em gavetas, dispondo de sistemas de inativação e de vedação dos gases para evitar que esses cheguem às áreas comuns onde circulam os visitantes e os funcionários (CAMPOS, 2007; KEMERICH et al., 2014).

Segundo Santos (2013), a principal vantagem do cemitério vertical reside na eficiência espacial frente à escassez de terras urbanas, servindo como alternativa viável em regiões com características geológicas que impossibilitem o enterro, porém, o potencial desses espaços, no tocante à integração com a paisagem urbana, é praticamente o mesmo de edifícios comerciais. Thompson (2015) pontua ainda que, apesar do incentivo à verticalização de cemitérios no Brasil ser em grande parte impulsionado por estudos sobre contaminação ambiental, esses primam pela construção de novos empreendimentos, privilegiando o mercado imobiliário e promovendo o distanciamento da morte e dos ritos religiosos.

Nesse contexto, a manutenção dos cemitérios como espaços não secularizados, torna-os um reduto de sobrevivência de histórias e vínculos familiares que se perpetuam, e um local de respeito, reflexão e homenagem aos falecidos (CARVALHO, 2012), que é valorizado na proposta dos cemitérios parque (ou jardim), recintos de integração social e com a natureza, que visam substituir a imagem de um local sombrio e triste por uma visão mais leve, humana e funcional (GAFSKI, 2018), ainda que neles a presença de símbolos religiosos seja moderada.

Seguindo uma influência dos projetos americanos, o cemitério parque exibe um modelo religioso austero, que valoriza a simplicidade em detrimento do luxo e da ostentação dos cemitérios com túmulos, mais encontrados em países de maioria católica, tais, como, Itália, França, Espanha e Portugal (FILHO et al., 2005).
No Brasil, o cemitério parque (Figura 1) é regulamentado pela Resolução n 335/03 do Conselho Nacional do Meio Ambiente CONAMA, e definido como predominantemente recoberto por jardins, isento de construções tumulares, no qual as sepulturas são identificadas por uma pequena lápide ao nível do chão.

Sua principal característica é a área verde com paisagismo harmonioso, que oferece a possibilidade de integração de espaços verdes - amenizando as características marcantes de poluição visual dos cemitérios tradicionais com túmulos cujos tamanhos e excesso de ornamentos fúnebres competem entre si - e colabora ainda com o fornecimento de serviços ecossistêmicos dentro do contexto urbano (LOBODA; DE ANGELIS, 2010; SANTOS, 2013; CLAYDEN et al., 2015).

Os serviços ecossistêmicos (SE) são os benefícios diretos e indiretos obtidos dos ecossistemas e, segundo a Millenium Ecosystem Assessment (2003), podem ser divididos em quatro categorias: (1) suporte (p. ex. formação do solo, fotossíntese, nutrientes e ciclagem de água); (2) aprovisionamento (p. ex. alimentos, combustíveis, água doce, produtos farmacêuticos naturais e químicos); (3) regulação (p. ex. regulação da qualidade do ar e da água, clima, controle de pragas e doenças); e (4) cultural (p. ex. enriquecimento espiritual, recreação e experiências estéticas).

A despeito do potencial das áreas cemiteriais urbanas na contribuição com serviços de suporte e aprovisionamento, neste trabaIho, concentramo-nos em sua influência reguladora e cultural.

\section{Procedimentos Metodológicos}

\section{1 Área de estudo}

O objeto de estudo foi o Cemitério Municipal Jardim da Paz, localizado no bairro Jardim Shangri-lá, em Tangará da Serra - MT, a $240 \mathrm{~km}$ da capital, com área total de 6,8 hectares. Inaugurado inicialmente com 4,6 hectares em 1985, o cemitério atingiu sua capacidade máxima em 2005 , com aproximadamente 5.346 túmulos horizontais, o que demandou a abertura de nova 

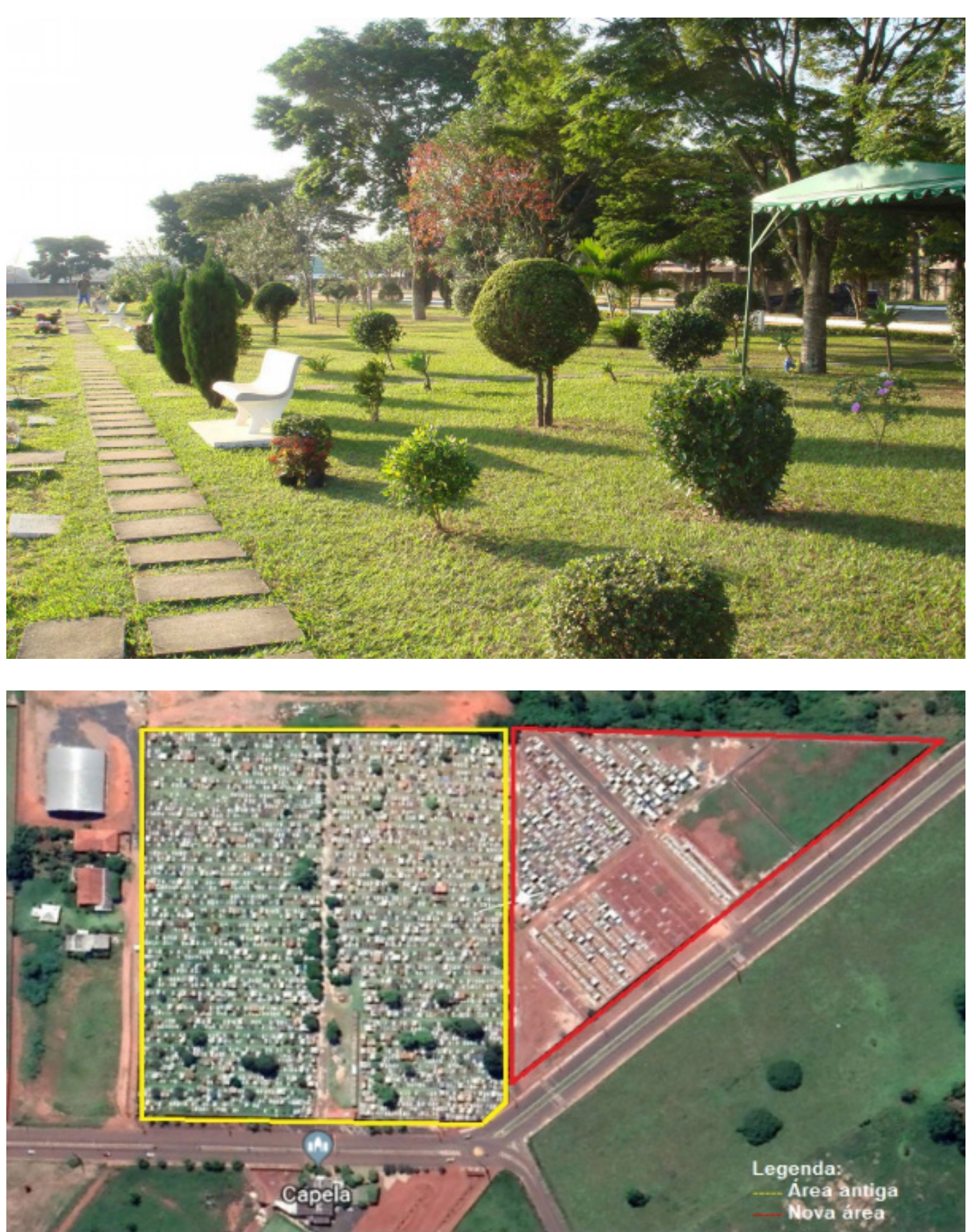

Figura 1 - Trecho arborizado do Cemitério Parque das Flores, em São José dos Campos/São Paulo.

Fonte: Página do cemitério Parque das Flores.

Disponível em: http://www.parquedasflores.com.br/ fotos.

Figura 2 - Vista aérea do Cemitério Municipal Jardim da Paz em Tangará da Serra - MT

Fonte: Google Earth (2019), adaptado pelos autores. 
área anexa de 2,2 hectares, com previsão para abrigar mais 3.000 túmulos tradicionais, conforme Figura 2.

A administração do cemitério foi concedida pela prefeitura municipal a uma empresa privada, concessionária que detém exclusividade dos serviços funerários no município por 30 anos a partir de 08 de fevereiro de 2000 e que tem o projeto de implantação de um cemitério parque no município com capacidade para 9.160 sepulturas (TANGARÁ DA SERRA, 2010).

\subsection{Caracterização da pesquisa e}

\section{INSTRUMENTO DE COLETA}

A pesquisa apresenta abordagem qualiquantitativa, voltada à observância das relações entre o mundo social e o mundo natural em determinado fenômeno e aos atributos mensuráveis da experiência (GERHARDT \& SILVEIRA, 2009) e natureza descritiva, envolvendo a observação, registro, classificação e interpretação, a fim de entender a relação entre as variáveis estudadas (COSTA SILVA, 2016), analisadas por meio de um estudo de caso, método que procura apresentar uma perspectiva global, tanto quanto possível completa e coerente do objeto de estudo (FONSECA, 2002).

A primeira etapa da pesquisa envolveu a revisão bibliográfica e da legislação pertinente, objetivando levantar informações acerca de questões sobre as tipologias de cemitérios, as normas de implantação, o paisagismo e os cemitérios como espaços multifuncionais.

A segunda etapa consistiu em duas visitas para observação in loco, que, orientadas por um roteiro estruturado, possibilitaram verificar a infraestrutura do cemitério, englobando tamanho, disposição e espaço entre os jazigos e arborização, enquanto entrevistas informais nortearam o levantamento de informações com a administradora do cemitério e com construtores, que relacionaram os materiais costumeiramente utilizados, as quantidades e os valores envolvidos na mão de obra necessária para a construção e a manutenção do local.
$\mathrm{Na}$ terceira etapa, com base nos dados obtidos, foi feita uma análise comparativa entre os cemitérios tradicionais e parque, buscando descrever características como funcionalidade, soluções ambientais, espaciais e paisagísticas, utilizadas como critério de comparação entre as duas tipologias.

\section{Resultados e Discussão}

O cemitério Jardim da Paz está localizado dentro do perímetro urbano, cujo entorno estão estabelecidos um hipermercado, um estabelecimento religioso, armazéns e residências. $\mathrm{O}$ acesso ao seu interior se dá por vias principais pavimentadas que levam aos ossuários e aos túmulos de modelos variados, adornados ou não. Há ocorrência de sepulturas parcialmente abertas ou desabadas, sem identificação, tomadas por vegetação e presença moderada de resíduos, tais, como: vasos, imagens, flores sintéticas e velas. Os gramados apresentam boas condições, embora praticamente não haja arborização.

O tipo de sepultamento predominante é por tumulação, no qual o caixão é colocado em caixas de alvenaria subterrâneas, em sua maioria com a parte superior visível e revestida por placas de cerâmica, embora haja também construções ostentosas em materiais nobres, como granito, mármore e vidro.

Os túmulos estão distribuídos de forma não padronizada, embora a Lei Municipal $n^{\circ}$ 1434/98 (TANGARÁ DA SERRA, 1998) discipline o ordenamento do cemitério e recomende as medidas de, no mínimo, 2,20 metros de comprimento, 0,90 centímetros de largura e 0,70 centímetros de altura para as sepulturas, com 0,30 centímetros de espaçamento entre elas. A Figura 3 apresenta o modelo de túmulo construído mais simples encontrado no cemitério.

Em cemitérios horizontais, o construtor começará a planejar a construção tumular após a solicitação do cliente e o material necessário será adquirido somente quando os prazos de construção e a natureza do túmulo estiverem definidos (DE PAULA; SABBADINI, 2005). 


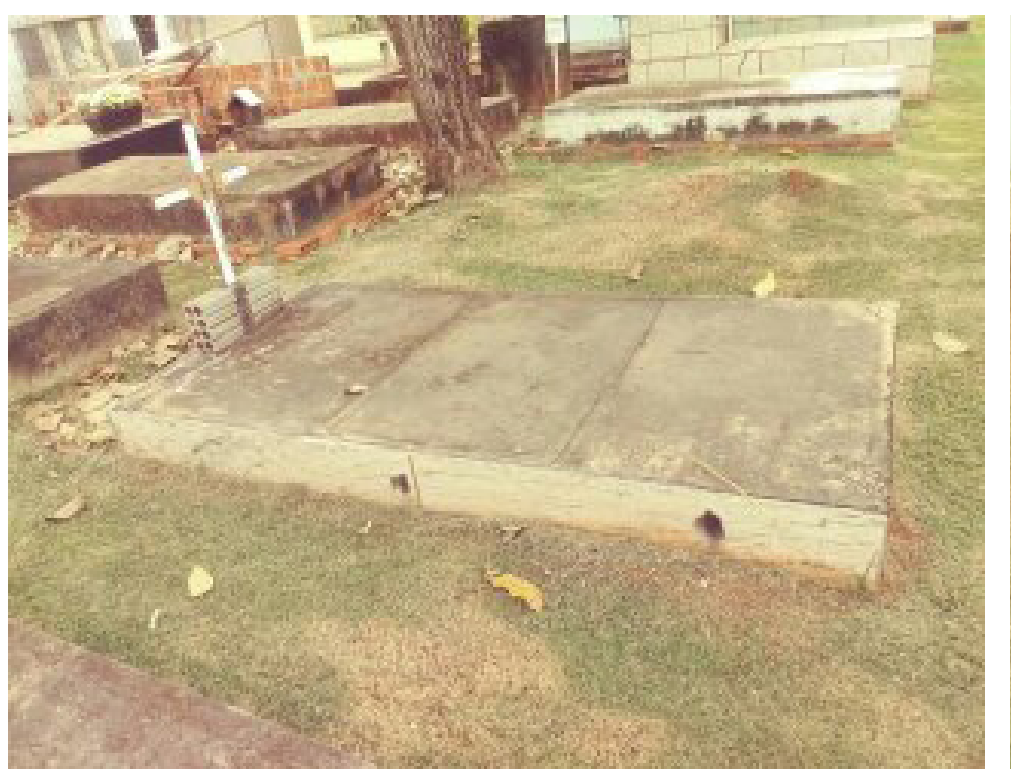

Para executar a construção de um túmulo nesse formato, sem adornos adicionais, o gasto médio é de $R \$ 560,00$ (quinhentos e sessenta reais), em valores pesquisados no mês de julho de 2019. Os materiais utilizados e seus respectivos preços estão relacionados na Tabela 1:

A areia, material básico na obra, é considerada fonte de preocupação ambiental, pois sua extração, quando ocorre por dragagem de leitos fluviais, provoca danos ao meio ambiente, como a supressão da vegetação nativa presente às margens do local de exploração, instabilidade de ambientes ribeirinhos, aumento da turbidez da água e modificações e desvios no leito do rio (NOGUEIRA, 2016). Além disso, a maioria das cavas abertas em várzeas para extração de areia resulta em lagoas que, frequentemente, acabam abandonadas e em processo de eutrofização, criando adensamentos e alterando o ambiente original em razão dos impactos cumulativos (MECHI \& SANCHES, 2010).

O segundo material mais consumido, o cimento, embora ofereça vantagens no preço e na durabilidade, é um grande inimigo do meio ambiente, por demandar em sua fabricação energia de combustíveis fósseis como petróleo e carvão, lançando na atmos-
Tabela 1 - Custo médio para construção de túmulo padrão em Tangará da Serra/MT.

\begin{tabular}{l|c}
\hline \multicolumn{1}{c|}{ Insumos e mão de obra } & Valor \\
\hline 5 carrinhos de areia & $\mathrm{R} \$ 60,00$ \\
\hline 2 carrinhos de brita & $\mathrm{R} \$ 26,00$ \\
\hline 2 sacos de cimento & $\mathrm{R} \$ 70,00$ \\
\hline $\begin{array}{l}1 \text { jogos de placas concreto } \\
\text { (5 unidades) }\end{array}$ & $\mathrm{R} \$ 180,00$ \\
\hline 180 tijolos & $\mathrm{R} \$ 124,00$ \\
\hline Mão de obra (diária) & $\mathrm{R} \$ 100,00$ \\
\hline Total & $\mathrm{R} \$ 560,00$ \\
\hline
\end{tabular}

Fonte: Dados da pesquisa, 2019.
Figura 3 - Modelo de túmulo padrão do cemitério Jardim da Paz Tangará da Serra/MT. Fonte: Os autores, 2019 
fera cerca de $5 \%$ das emissões globais de dióxido de carbono $\left(\mathrm{CO}_{2}\right)$, um gás de efeito estufa responsável por potencializar mudanças climáticas (WBCSD, 2002).

Além disso, quando se transforma um solo outrora permeável, em uma superfície impermeabilizada resultante da construção de edificações, pavimento ou outras obras, a condição de escoamento das águas sofre grande alteração (JUSTINO et al., 2011), apresentando os efeitos mais notáveis no aumento do escoamento superficial e na diminuição da infiltração, fatores diretamente relacionados à ocorrência de inundações urbanas (FONTES \& BARBASSA, 2003).

Nos períodos de alta pluviosidade, o escoamento ainda inunda os túmulos mais vulneráveis e, após a passagem pela área do cemitério, essas águas são eventualmente lançadas na rede pluvial urbana e canalizadas para os corpos de água da região, carregando substâncias do interior do cemitério (BAUAB; LEME, 2013).

Frente a isso, as Resoluções n 335/03 e 368/06 - CONAMA, dispõem que a área de fundo das sepulturas em solos com coeficientes de permeabilidade entre $10^{-5}$ e $10^{-7} \mathrm{~cm} / \mathrm{s}$ deve manter uma distância mínima de 1,5 metro do nível máximo do aquífero freático, medido no fim da estação das cheias, e em solos mais permeáveis é necessário que a distância seja, no mínimo, de 10 metros. Além disso, área de sepultamento deverá manter um recuo mínimo de cinco metros em relação ao perímetro do cemitério, que deverá ser ampliado, caso necessário, em função da caracterização hidrogeológica da área.

De acordo com dados do Departamento de Informática do Sistema Único de Saúde (DATASUS, 2019), o número disponível de óbitos por ocorrência registrados no município foi de 524 em 2017. Considerando as recomendações das resoluções e tendo em vista que a nova área em uso do cemitério tem previsão para comportar 3.000 jazigos, nesse ritmo, em pouco mais de 5 anos, o espaço destinado a novos sepultamentos estará esgotado.

Assim, se continuada a opção por cemitério horizontal, tanto tradicional quanto parque, a ação mais imediata é aquisição de mais área destinada aos sepultamentos. Frente a isso, deve-se conside- rar não apenas o aspecto econômico dessa opção, mas também a adequação do local às exigências legais, uma vez que a Resolução $n^{\circ}$ 335/03 determinou que até o fim de 2010 todos os cemitérios deveriam passar por processo de licenciamento ambiental, exigindo o cumprimento rigoroso das normas ambientais.

A demanda, no caso de óbitos, relaciona-se diretamente ao crescimento da população, sendo que à época de construção da maioria dos cemitérios municipais não se pensava sobre o problema de lotação (MATOS, 2001; PAULA, 2005). Embora comumente se estipulem prazos para a retirada dos restos mortais das sepulturas, com translado para ossuários (no caso de Tangará da Serra são previstos 3 anos), Thompson (2015) pontua que a capacidade dos cemitérios é afetada pela existência das covas perpétuas, que impedem a rotatividade do uso do solo, limitando o reaproveitamento do espaço.

No cemitério parque, assim como no cemitério tradicional, os jazigos são subterrâneos (Figura 4), mas a superfície, ao invés de construções, é recoberta por gramados e os túmulos identificados por uma placa apenas, com a forma variando de acordo com as regras de cada cemitério (CEMITÉRIO SEM MISTÉRIO, 2017).

Ainda que seja necessário um espaço considerável para sua implantação, por comportar várias gavetas subterrâneas, há uma relativa otimização do uso do espaço no cemitério parque em comparação com o modelo tradicional. Embora não alcance a economia de espaço ofertada por um cemitério vertical, deve, como nesse, garantir que os fundos dos túmulos sejam estanques, a fim de evitar a infiltração e contaminação do lençol freático (PACHECO, 2000).

Se considerada unicamente a questão de falta de espaço, a verticalidade se configura uma solução alternativa para atender às necessidades na área urbana (HARIYONO, 2015), mas ainda prevalece a ideia de que o cemitério é um local de identificação comum, frequentemente relacionada com uma casa ou unidade residencial, mesmo que essa já não mais exista (MOTTA, 2009).

Os cemitérios tradicionais costumam ter uma estrutura física mais desoladora, uma vez que são construídos muitos monumentos e 
lápides, que se deterioram com o passar do tempo, passando a sensação de um ambiente pesado e desconfortável, enquanto os cemitérios verticais apresentam apenas resquícios longínquos da sacralização da morte (THOMPSON, 2015).

O cemitério parque, no entanto, ao contrário do clássico ambiente fúnebre, destina seus recursos a criar um espaço sereno e agradável para aqueles que o visitam (CEMITÉRIO SEM MISTÉRIO, 2017), primando pela não distinção econômica, social, racial, credo religioso ou de qualquer natureza, alcançada pela supressão da ostentação nas construções, que é substituída por jardins naturais, nivelando a todos pelo uso dos gramados, com objetivo de criar um ambiente próprio para momentos de evocação e saudade (SOBRINHO, 2002).

Essa configuração mais sensível e ecológica do cemitério parque é o diferencial que oportuniza o aproveitamento diverso da área e desfrute de seu espaço, pois os gramados, espaços amplos, árvores e demais elementos da natureza, são fatores que estimu- vendo a saúde e bem-estar (SZEREMETA, 2013), uma vez que as pessoas ficam mais satisfeitas com os caminhos compostos de vegetação arbórea do que com espaços vazios (HOLMAN et al., 1997).

O conjunto de sensações subjetivas das pessoas, em relação a determinadas características do ambiente, é chamado conforto ambiental, que é afetado por inúmeros fatores, tais, como, a incidência da radiação solar nas construções, que aliada à ausência de vegetação, causa aumento da temperatura, modifica a circulação do vento, a umidade e as chuvas, contribuindo para a formação de ilhas de calor, e anomalias térmicas, onde o ar da cidade se torna mais quente que $o$ ar das regiões vizinhas (PAULA, 2004).

A vegetação absorve $90 \%$ da radiação visível e $60 \%$ da infravermelha, com o excedente transmitido entre as folhas ou refletido e, em uma cobertura vegetal de pelo menos $20 \%$, grande parte da radiação solar recebida é usada para evaporação, causando um esfriamento que pode reduzir a temperatura do ar em até $5^{\circ}$ C (RIVERO, 1986; TAHA et al., 1991). A atuação sobre esses fatores depende do tipo de vegetação, do porte, da idade, da estação do ano e das formas de associação, como também, da relação entre as edificações e os recintos urbanos, enfatizando-se que a vegetação interage com o conjunto de elementos climáticos (MASCARÓ et al., 2008).

A arborização também atua na conservação das águas, uma vez que, em âmbito mundial, até $40 \%$ da precipitação terrestre é gerada pela transpiração vegetal e pela evaporação do solo, que influenciam as características da água e o ciclo hidrológico de mananciais (BALBINOT, 2008; UNESCO, 2018).

No cemitério parque, a composição vegetal geralmente é distribuída ao longo de bosques, canteiros e gramados, requerendo cuidados constantes, que envolvem rega, adubação, controle fitossanitário, poda e replantio. A sua manutenção tem interferência direta com a qualidade aprazível do campo cemiterial, servindo para uma boa drenagem do terreno e fixação de solos das áreas sujeitas a erosão, além de elemento ornamental (SOBRINHO, 2002). Nesse caso, pode-se inferir que a despesa maior 
que incorre na implantação de um cemitério parque é aquela demandada pelos cuidados com o paisagismo, uma vez que a vegetação necessita de cuidados constantes, necessários para que se mantenha saudável.

É importante destacar que a manutenção intensiva do gramado é um contribuinte significativo para as emissões de gases de efeito estufa, sendo que a extensão dessa liberação depende do manejo e do corte de baixa frequência, permitindo que o gramado atue como sequestrador líquido do carbono atmosférico (MILESI et al., 2005; CLAYDEN et al., 2015).

Como Tangará da Serra apresenta duas estações bem definidas, uma chuvosa, de outubro a abril, e outra seca, de maio a setembro (DALLACORT et al., 2011), em relação à adequação do projeto paisagístico, o emprego de espécies nativas da região, tanto por sua adaptação ao clima de duas estações e ao estresse hídrico quanto por sua importância ecológica, beleza e como patrimônio natural, é favorecido, com precedência ao uso de espécies exóticas (ITII et al., 2012; GONÇALVES, 2015).

Enquanto os potenciais benefícios para a saúde mental e bem-estar promovidos pelo contato com espaços verdes urbanos estão bem documentados, o foco aqui está na oportunidade única oferecida pelas áreas cemiteriais urbanas para prestação de vários serviços ecológicos importantes para a sociedade.

\section{Considerações FinaIs}

Os cemitérios, de modo geral, geram impactos na paisagem urbana, mas como espaços necessários no contexto ambiental e cultural, podem ser pensados dentro de um planejamento voltado a minimizar problemas ambientais e melhorar a qualidade de vida da população.

Neste trabalho, a comparação entre os dois modelos pensados para o município de Tangará da Serra/MT, de cemitério tradicional e parque, apontou que o primeiro apresenta desvantagens em relação aos custos de manutenção das construções, na utilização do espaço e na arborização.
Em termos de manutenção, em virtude das muitas e diferentes edificações, o cemitério tradicional demanda maior intervenção dos construtores e, caso isso não ocorra, o espaço cemiterial se deteriora, interferindo na paisagem urbana e tornando-se passível de contaminação.

Na proposta de cemitério parque, as construções estão presentes devido aos fins sanitários e uma área ampla ainda é necessária, mas o maior custo é relacionado ao paisagismo, que deve ser cuidadosamente projetado para se inserir no contexto urbano e natural circundante, a fim de oferecer os benefícios ambientais relacionados ao conforto térmico, conservação e beleza cênica, além de favorecer as funções ecológicas e valorização do patrimônio natural.

A adoção de tipologias diferentes de cemitério contribui para a alteração no peso simbólico atribuído a esses locais, que são vistos como identitários, ainda que o cemitério parque, devido a ser um formato ainda pouco difundido, muitas vezes não cause o sentimento de reconhecimento como um cemitério tradicional.

Nesse quesito, no município de Tangará da Serra/MT, faz-se necessário um levantamento criterioso dos investimentos requeridos para a implantação de um cemitério parque, a fim de verificar sua viabilidade econômica e adequação ambiental, tanto quanto uma pesquisa junto à população para averiguar a disposição quanto à aceitação dessa tipologia, considerando a proposta de conexão com a natureza, que além de contribuir com a qualidade ambiental e de vida, pode auxiliar na compreensão da morte como uma ocorrência cíclica e natural do ponto de vista sociocultural.

\section{REFERÊNCIAS BibliográficAS}

ANDRADE, R. V. O Processo de Produção dos Parques e Bosques Públicos de Curitiba. Curitiba, 2001. 120 p. Dissertação (Mestrado em Geografia) -Setor de Ciências da Terra, Universidade Federal do Paraná. Disponível em: http:// observatoriogeograficoamericalatina.org.mx/egal8/Geografiasocioeconomica/ Geografiaurbana/70.pdf. Acesso em: 12 set. 2019.

BALBINOT, R.; OLIVEIRA, N.K.; VANZETTO, S.C. PEDROSO, K. VALERIO, A.F. O pape da floresta no ciclo hidrológico em bacias hidrográficas. R. Amb., 4:131-149, 2008. 
Disponível em: https://revistas.unicentro.br/index.php/ambiencia/article/view/\%20 294/1892. Acesso em: 18 set. 2019.

BARTALINI, V. Notas sobre paisagem e o ensino de paisagismo. Paisag. Ambiente: Ensaios, São Paulo, v. 30, n. 43, 2019. Disponível em: http://www.revistas.usp.br/ paam/article/view/153638/157626. Acesso em: 09 jun. 2020.

BAUAB, K. C.; LEME, R. C. B. Análise do processo de implementação de cemitérios da zona rural de Francisco Beltrão - PR. Revista Perspectiva Geográfica. v. 8, n. 9 2013. Disponível em: http://e-revista.unioeste.br/index.php/pgeografica/article/\%20 view/6851/7046\#. Acesso em: 15 maio 2019.

BEECHER J.: Avoided Cost: an Essential Concept For Integrated Resource Planning, Center for Urban policy and the Environment, Indiana University-Purdue University, 1995. Disponivel em: https://opensiuc lib siu.edu/cgi/viewcontent.cgi?referer=https:/ www.google.com/\&httpsredir=1\&article=1321\&context=jcwre. Acesso em: 16 ago. 2019. BRASIL. CONAMA - Conselho Nacional de Meio Ambiente. Resolução $n^{\circ} .335$ de 03 de abril de 2003. Dispõe sobre o licenciamento de cemitérios. Disponível em:

http://www2.mma.gov.br/port/conama/legiabre.cfm?codlegi=359. Acesso em: 21 setembro 2018.

BRASIL. CONAMA - Conselho Nacional de Meio Ambiente. Resolução $\mathrm{n}^{\circ} . \mathbf{3 6 8}$ de 28 de março de 2006. Dispõe sobre o licenciamento de cemitérios. Brasília, 2006. Disponível em: http://www2.mma.gov.br/port/conama/legiabre.cfm?codlegi=488. Acesso em: 21 set. 2018

CAMPOS, A. P. S. Avaliação do potencial de poluição no solo e nas águas subterrâneas decorrente da atividade cemiterial. 2007. 141f. Dissertação (Mestrado em Saúde Pública) - Universidade de São Paulo, Faculdade de Saúde Pública, São Paulo, 2007. Disponível em: https://teses.usp.br/teses/\%20dispon\%C3\%ADveis/6/6134/ tde-25112007-172840/pt-br.php. Acesso em: 21 set. 2018.

CARNEIRO, V. S. Impactos causados por necrochorume de cemitérios: Meio Ambiente e saúde pública. XV Congresso Brasileiro de Águas Subterrâneas. Natal. Rio Grande do Norte. 2008. Disponível em: https://aguassubterraneas.abas.org/asubterraneas/ article/view/21956/14325. Acesso em: 08 maio 2019.

CARVALHO, Hugo Pereira de. A inclusão do cemitério no espaço da cidade. 2012. 127 f. Dissertação (Mestrado) - Curso de Arquitetura, Universidade Técnica de Lisboa, Lisboa, 2012. Disponível em: https://www.repository.utl.pt/handle/10400.5/5986. Acesso em: 07 set. 2019.

CEMITÉRIO SEM MISTÉRIO. Cemitério tradicional x cemitério parque: quais as diferenças? 2017. Disponível em: https://cemiteriosemmisterio.com.br/cemiterio-

CLAYDEN, A.; GREEN, T.; HOCKEY, J.; POWELL, M. Cutting the lawn: Natural burial and its contribution to the delivery of ecosystem services in urban cemeteries. Urb Forestry \& Urban Greening, p.1-8, 2017. Disponível em: https://www.sciencedirect. com/science/article/pii/S1618866717303138. Acesso em: 15 set. 2018.

CONTI, J. B. Geografia e Paisagem. Ciência e Natura, Santa Maria, v. 36 Ed. Especial 2014, p. 239-245. Disponível em: https://periodicos.ufsm.br/cienciae\%20natura/article 2014, p. 239-245. Disponível em: https:/p
view/13218. Acesso em: 09 jun. 2020.

COSTA SILVA, C. M.; CARVALHO, J. R. M.; LUZ, J. R. M.; ALBUQUERQUE, L. S OLIVEIRA, P. S. Análise das Metodologias e Técnicas de Pesquisas sobre os Ativos Intangíveis nos Eventos da Área Contábil no Brasil. Revista eletrônica do Alto Vale do Itajaí (Reavi), v, 5, n . 7, 2016. Disponível em: http://www revistas.udesc.br/index. php/reavi/article/view/2316419005072016037. Acesso em: 3 maio 2019.
DALLACORT, R.; MARTINS, J. A.; INOUE, M. H.; FREITAS, P. S. L.; COLETTI, A, J. Distribuição das chuvas no município de Tangará da Serra, médio norte do estado de Mato Grosso, Brasil. Acta Sci., Agron. (Online), Maringá, v. 33, n. 2, p. 193-200, 2011. Disponivel em: https://www. scielo br/scielo php?script=sci arttext\&pid=S1807 $86212011000200001 \& \operatorname{lng}=e n \& n r m=$ iso. Acesso em: 16 maio 2019.

FILHO, C. H. M. M.; OlIVEIRA, E. C. R.; MOREIRA, F. B.; FRANCISCO; V. S. A comunicação através da arte tumular. Monografia (Curso de Publicidade e Propaganda), 2005. UNIVAP. Disponível em: http://biblioteca.univap.br/dados/ 00002 b/00002b7f.pdf. Acesso em: 13 set. 2019.

FONSECA, J. J. S. Metodologia da pesquisa científica. Fortaleza: UEC, 2002. Apostila. Disponível em: https://books.google.com.br/books?id=oB5 2 2SChpSEC\&

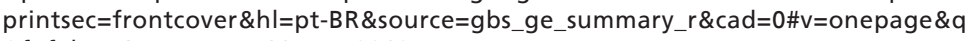
$\& f=$ false. Acesso em: 11 set. 2019.

FONTES; A. R. M.; BARBASSA, A. P. Diagnóstico e Prognóstico da Ocupação e da Impermeabilização Urbana. RBRH - Revista Brasileira de Recursos Hídricos, São Paulo, v. 8, n.2, abr/jun 2003. p. 137 - 142. Disponível em: https://www.abrhidro.org. $\mathrm{br} / \mathrm{SGCv} 3 /$ publicacao. $p h p ? \mathrm{PUB}=1 \& I \mathrm{D}=36 \& \mathrm{SUMARIO}=526$. Acesso em: 04 maio 2019 GAFSKI, K. R.; GOIS, V. F.; PAGNO, D. K. Cemitério-Parque: Um Novo Conceito de Cemitério para o Município de Capanema-PR. Revista Científica Multidisciplinar Núcleo do Conhecimento. Ano 03, Ed. 07, Vol. 04, pp. 106-129, 2018. Disponível em: https://www nucleodoconhecimento.com br/arquitetura/cemiterio-parque. Acesso em: 10 abr. 2019.

GERHARDT, T. E.; SILVEIRA, D. T. (organizadoras). Métodos de Pesquisa. $1^{\text {a }}$ Ed. Porto Alegre: Editora da UFRGS, 2009. Disponível em: http://www.ufrgs.br/cursopgdr/ downloadsSerie/derad005.pdf. Acesso em: 3 maio 2018.

HARIYONO, W. P. Vertical Cemetery. International Conference on Sustainable Design, Engineering and Construction. Procedia Engineering, v. 118, p. 201-214, 2015 Disponível em: https://www.sciencedirect.com/science/article/pii/S1877705815020743. Acesso em: 10 jun. 2020.

HOLMAN, C. D.; DONOVAN, R. J.; CORTI, B. Factors influencing the use of physical activity facilities: results from qualitative research. Health Promotion Journal of Australia: Official Journal of Australian Association of Health Promotion Professionals, Vol. 6, No. 1, 1996 Apr: 16-21. Disponivel em: https://search.informit. com.au/documentSummary; $\mathrm{dn}=4$ 61582631812285;res= IELHEA. Acesso em: 12 set. 2019.

JUSTINO, E. A.; PAULA, H. M.; PAIVA, E. C. R. Análise do efeito da impermeabilização dos solos urbanos na drenagem de água pluvial do município de Uberlândia-MG. Espaço em Revista, v. 13, p. 16-38, 2011. Disponível em: https://www.revistas.ufg.br/ espaco/article/view/16884. Acesso em: 10 set. 2019

KEMERICH, P. D. C.; BIANCHINI, D. C.; FANK, J. C.; BORBA, W. F.; WEBER, D. P.;

UCKER, F. E. A questão ambiental envolvendo os cemitérios no Brasil. Revista do Centro do Ciências Naturais e Exatas - UFSM, Santa Maria. Revista Monografias Ambientais - REMOA, V. 13, N. 5 (2014): Edição Especial LPMA/UFSM, p. 3777-3785. Disponivel em: https://periodicos.ufsm.br/remoa/article/view/14506. Acesso em: 21 set. 2018.

LIMA, I. M. O cemitério como espaço devocional: um estudo sobre a devoção a Irmã Benigna (The cemetery as devotional space: a study about the devotion to sister Benigna). HORIZONTE - Revista de Estudos de Teologia e Ciências da Religião, Belo Horizonte, p. 381-402 mar. 2013. ISSN 2175-5841. Disponivel em: http:/periodicos. pucminas.br/index.php/horizonte/article/view/3971. Acesso em: 21 set. 2018. 
LOBODA, C. R.; DE ANGELIS, B. L. D. Áreas Verdes Públicas Urbanas: Conceitos, usos e funções. Ambiência - Revista do Centro de Ciências Agrárias e Ambientais, $v$. 1 , n. article/viewFile/157/185. Acesso em: 08 set. 2019.

MASCARÓ, J. J.; DIAS, A. P. Á.; GIACOMIN, S. D. Arborização pública como estratégia de sustentabilidade urbana. Passo Fundo: Faculdade de Engenharia e Arquitetura FEAR. Universidade de Passo Fundo, 2007. Disponível em: https://www.usp.br/nutau/ CD/29.pdf. Acesso em: 12 set. 2019.

MATOS, B. A. Avaliação da ocorrência e do transporte de microorganismos no aqüífero freático do cemitério de Vila Nova Cachoeirinha, município de São Paulo. 2001. $172 \mathrm{f}$. Tese (Doutorado em Recursos Minerais e Hidrogeologia) -Universidade de São Paulo, São Paulo, 2001. Disponível em: https://aguassubterraneas.abas.org/ asubterraneas/article/view/22635. Acesso em: 21 set. 2018.

MECHI, A.; SANCHES, D. L. Impactos ambientais da mineração no Estado de São Paulo. Estud. av., São Paulo, v. 24, n. 68, p. 209-220, 2010. Disponível em: http:/l www.revistas.usp.br/eav/article/view/10475. Acesso em: 06 maio 2019.

MILESI, C., RUNNING, S. W., ELVIDGE, C. D., DIETZ, J. B., TUTTLE, B. T., \& NEMANI, R. R. Mapping and Modeling the Biogeochemical Cycling of Turf Grasses in the United States. Environmental Management, 36(3), 426-438, 2005. Disponível em: https:// www.academia.edu/4620707/Mapping_and_Modeling_the_Biogeochemical_Cycling_of Turf_Grasses_in_the_United_States. Acesso em: 12 set. 2019.

MILLENNIUM ECOSYSTEM ASSESSMENT (MEA), 2003. Ecosystem and Human WellBeing: A framework for assessment. Washington, D.C.: Island Press. Disponivel em: http://pdf.wri.org/ecosystems_human_wellbeing.pdf. Acesso em: 11 set. 2019.

MINISTÉRIO DA SAÚDE - DEPARTAMENTO DE INFORMÁTICA DO SISTEMA ÚNICO DE SAÚDE - DATASUS. MORTALIDADE - MATO GROSSO: Óbitos Por Ocorrência segundo Município. Disponível em: http://tabnet.datasus.gov.br/cgi/tabcgi.exe?sim/cnv/obt10mt. def. Acesso em: 12 set. 2019

MOTTA, A. Formas tumulares e processos sociais nos cemitérios brasileiros. Rev. bras. Ci. Soc., São Paulo, v. 24, n. 71, p. 73-93, out. 2009. Disponível em: https://www. scielo.br/scielo.php?script=sci_arttext\&pid=S0102-69092009000300006\&lng =pt\&nrm=i so. Acesso em: 10 jun. 2020

NOGUEIRA, G. R. F. A extração de areia em cursos de água e seus impactos: proposição de uma matriz de interação. Trabalho Final de Curso (Engenharia Sanitária e Ambiental). Universidade Federal de Juiz de Fora, UFJF, 2016. Disponível em: http://www.uffif.br/engsanitariaeambiental/files/2014/02/TFC Vers\%C3\%A3oFinal. pdf. Acesso em: 04 maio 2019

PACHECO, A. Cemitérios e meio ambiente. 2000. 168f. Tese (Livre Docência) Universidade de São Paulo, Instituto de Geociências, São Paulo. Disponível em: https://teses.usp.br/teses/disponiveis/livredocencia/44/tde-23062015-131326/pt-br.php. Acesso em: 10 set. 2019.

PAULA, L. S. Planejamento da capacidade de cemitérios: um estudo de caso no Cemitério Municipal de Resende. 2005; Trabalho de Conclusão de Curso (Graduação em Administração) - Universidade Estácio de Sá. Disponível em: https://www.aedb.br/ seget/arquivos/artigos05/332_Planecapacidade.pdf. Acesso em: 06 maio 2019.

PAULA, R. Z. R. Influência da vegetação no conforto térmico do ambiente construído Dissertação (Mestrado em Engenharia Civil) Campinas, 2004. Disponível em: http:// taurus.unicamp.br/bitstream/REPOSIP/257742/1/Paula_RobertaZakiaRigitanode_M.pdf. Acesso em: 12 set. 2019
PIZZOL, K. M. S. A. Reflexões e descobertas na paisagem de Cemitérios Urbanos: um olhar entre muros em cemitérios de João Pessoa-PB. Caminhos de Geografia, v. $12, n$. 37, 2011. Disponível em: http://www.seer.ufu.br/index.php/caminhosde\%20geografia/ article/view/16312. Acesso em: 10 set. 2019.

RIVERO, R. Arquitetura e clima. Acondicionamento térmico natural. Porto Alegre: DC Luzzatto, 1986.

SANTOS, A. S. Espaços cemiteriais e suas contribuições para a paisagem e meio ambiente urbanos. Revista Labverde, n. 6, p. 85-105, 2013. Disponível em: http:// www.revistas.usp.br/revistalabverde/article/view/61879. Acesso em: 09 maio 2020. SANTOS, F. R. N. ; LIMA, J. J. S. Uma abordagem historiográfica das práticas de sepultamento entre os séculos XVIII a XIX: estudo de caso da igreja de Mazagão Velho. In: III Encontro de Discentes, 2017, Macapá. Anais do III Encontro de Discentes de História da UNIFAP, 2017. v. 2. p. 1-13. Disponível em: https://www2.unifap.br/ cepap/files/2017/10/FERNANDO-E-JELLY-UMA-ABORDAGEM-HISTORIOGR\%C3\%81FICA DAS-PR \%C3\%81TICAS-DE-SEPULTAMENTO-ENTRE-OS-S\% C3\%89CULOS-XVIII-A-XIX.pdf. Acesso em: 21 set. 2018

SILVA, J. A. Direito Ambiental Constitucional. Editora Malheiros, São Paulo. 2001. SOBRINHO, B. M. R. Cemitério e meio ambiente. Revista Educação Ambiental em Ação, v. 1, n. 3, 2002. Disponível em: http://www.revistaea.org/artigo. php?idartigo $=\% 20107$. Acesso em: 20 ago. 2019 .

SZEREMETA, B.; ZANNIN, P. H. T. A importância dos parques urbanos e áreas verdes na promoção da qualidade de vida em cidades. Raega - O Espaço Geográfico em Análise, [S.I.] v. 29, p. 177-193, dez. 2013. Disponível em: https://revistas.ufpr.br/ raega/article/view/30747/21483. Acesso em: 12 set. 2019.

VÊNCIO, F. N. C.; CAMARGO, R. P.; OLIVEIRA, R. S.; COSTA, M. A.; GREGORIN R. A. Estudo de Viabilidade Ambiental (EVA) do cemitério Parque dos Girassóis. Parelheiros, São Paulo. 2012. Disponível em: https://www.prefeitura.sp.gov.br/cidade/ secretarias/upload/meio_ambiente/arquivos/girassoiseva.pdf. Acesso em: 15 de maio de 2019.

TAHA, H.; AKBARI, H.; ROSENFELD, A. Heat island and oasis effects of vegetative canopies: micro-meteorological field-measurements. Theoretical and Applied Climatology 44: 123-138, 1991. Disponível em: https://link.springer.com/ article/10.1007/BF00867999. Acesso em: 3 set. 2019.

TANGARÁ DA SERRA. Prefeitura Municipal. Lei Municipal $n^{\circ}$ 1434, de 04 de julho de 1998. Aprova o regulamento geral dos serviços de cemitérios no município de Tangará da Serra-MT e dá outras providências. Disponível em: https://leismunicipais. com.br/a1/mt/t/tangara-da-serra/lei-ordinaria/1998/143/1434/lei-ordinaria-n-1434-1998aprova-o-regulamento-geral-dos-servicos-de-cemiterios-no-municipio-de-tangara-daserra-mt-e-da-outras-providencias. Acesso em: 04 maio 2019.

TANGARÁ DA SERRA. Prefeitura Municipal. Tangará da Serra deverá ter cemitério parque. Assessoria de Imprensa, julho, 2010. Disponível em:

https://www.tangaradaserra.mt.gov.br/Imprensa/Noticias/\%20Tangara-da-serra-deverater-cemiterio-parque-4562/. Acesso em: 10 jun. 2020.

THOMPSON, B. Cemitérios verticais, espaço urbano e meio ambiente: O novo discurso científico universitário de incentivo a verticalização do cemitério e cremação. Primeiros Estudos, (7), 07-26, 2015. Disponível em: http://www.revistas.usp.br/ primeirosestudos/article/view/84289/106958. Acesso em: 3 set. 2019.

UNESCO (2018) WWAP (United Nations World Water Assessment Programme)/UNWater. 2018. The United Nations World Water Development Report 2018: Nature- 
Based Solutions for Water. Paris, UNESCO. Disponível em: https://www.unwater.org/ publications/world-water-development-report-2018/. Acesso em: 22 mar. 2018.

WORLD BUSINESS COUNCIL FOR SUSTENTAINABLE DEVELOPMENT - WBCSD. The

cement sustainability initiative: our agenda for action. 2002. Disponível em: https:// docs.wbcsd.org/2002/06/TheCementSustInitiative.pdf. Acesso em: 04 de maio de 2019.

Ana Paula Silva de Andrade

Universidade do Estado de Mato Grosso - UNEMAT. Programa de Pós-graduação em Ambiente e Sistemas de Produção Agrícola

Rodovia Inácio Bittencourt, n 7, Jardim Aeroporto CEP 78300-000.

Tangará da Serra - MT.

https://orcid.org/0000-0001-5017-8526

anapsakm@hotmail.com/ ana.andrade@unemat.br

\section{Cleci Grzebieluckas}

Universidade do Estado de Mato Grosso - UNEMAT. Programa de Pós-graduação em Ambiente e Sistemas de Produção Agrícola

Tangará da Serra - MT.

https://orcid.org/0000-0001-9786-9607

cleci@unemat.br

Flávio Amaral Oliveira

Universidade do Estado de Mato Grosso - UNEMAT. Programa de Pós-graduação em Ambiente e Sistemas de Produção Agrícola

Rodovia Inácio Bittencourt, n 7, Jardim Aeroporto CEP 78300-000.

Tangará da Serra - MT.

https://orcid.org/0000-0001-9487-0557

flavioamaral.mt@gmail.com

Rodrigo Henrique Pinheiro

Universidade do Estado de Mato Grosso - UNEMAT. Programa de Pósgraduação em Ambiente e Sistemas de Produção Agrícola

Rodovia Inácio Bittencourt, n² 7, Jardim Aeroporto CEP 78300-000.

Tangará da Serra - MT.

https://orcid.org/0000-0002-0496-4216

rodrigohenriquemt@gmail.com

Notas do Editor:

Data de submissão: 25/03/2020

Aceite: 15/06/2020

Revisão: 